\title{
COSMOVISÃO CRISTÃ E ECOLOGIA: UM DIÁLOGO NECESSÁRIO PARA A COMPREENSÃO DA CRISE AMBIENTAL
}

\author{
CHRISTIAN AND ECOLOGY COSMOVISION: \\ A NECESSARY DIALOGUE TO UNDERSTAND \\ THE ENVIRONMENTAL CRISIS
}

\section{Joel Silva dos Santos ${ }^{1}$}




\section{RESUMO}

A crise ambiental ultrapassa os limites da ciência ecológica, pois ela pode ser entendida como uma crise de civilização com aspectos políticos, sociais e econômicos. A sua compreensão requer um olhar contextualizado, holístico e integral sobre a sociedade humana e a Criação. Dessa forma, uma visão distorcida e dualista do entendimento da estrutura criacional e de sua extensão pode comprometer a visão interdisciplinar e profunda (aspectos éticos e morais) dos problemas ambientais que afetam a sociedade pósmoderna. Sendo assim, é diante deste contexto que este artigo se insere, tendo como objetivo principal, verificar a contribuição de uma cosmovisão bíblica reformada e da ciência ecológica profunda na compreensão dos problemas ambientais e na promoção da sustentabilidade ambiental. Para a realização da pesquisa, inicialmente foi feito um levantamento bibliográfico a respeito da temática em questão: ecologia e cosmovisão cristã. Posteriormente, foram desvelados alguns pressupostos do humanismo confessional que possibilitaram a revolução técnocientífica e o surgimento de uma ciência experimental e cartesiana. Em seguida, foram verificadas as categorias teológicas: Criação, Queda e Redenção, basilares no pensamento cristão reformado neocalvinista e os pressupostos da Ecologia Profunda para se chegar a uma compreensão integral e holística da crise ambiental e de seus desdobramentos na sociedade pós-moderna. A pesquisa revela que uma visão distorcidaldualista do pensamento cristão ao longo da Idade Média fundamentada em Platão e Aristóteles comprometeu o envolvimento dos cristãos pela causa ambiental e o seu real entendimento. A ciência moderna experimental com seus pressupostos racionais e desenvolvimentista contribui diretamente para degradação ambiental e a separação (dicotomia) homem e natureza. O resgaste de uma cosmovisão bíblica reformada, com base na escola de pensamento neocalvinista e o surgimento da ecologia profunda, contribuem para o debate ecológico contextualizado e holístico, além do engajamento da comunidade cristã e sociedade em geral no enfrentamento da crise ambiental e promoção da sustentabilidade ambiental. O diálogo salutar entre fé (teologia pública) e ciência (ecologia profunda) estabelece bases epistemológicas para a busca de uma sociedade economicamente viável, socialmente justa e ecologicamente sustentável. 


\title{
PALAVRAS-CHAVE \\ Cosmovisão Cristã Reformada, Ecologia Profunda, Pensamento sistêmico.
}

\begin{abstract}
The compreention of the environmental crisis needs a contextualized, holistic and integral view about the human society and its relation with the Creation. A distorted and dualistic view of the understanding of the creational structure and its extension can compromise the interdisciplinary and profound view (ethical and moral aspects) of the environmental problems that affect postmodern society. It is in this context that this article is inserted, with the main objective of verifying the contribution of a Reformed biblical worldview and the deep ecological science in the understanding of the environmental problem. For the accomplishment of the research, initially a bibliographical survey was made on the subject in question and unveiled some assumptions of confessional humanism. Then the theological categories: Creation, Fall, and Redemption were found, basilar in reformed Christian thought neocalvinist and the presuppositions of Deep Ecology. The research reveals that a distorted \dualistic view of Christian thought throughout the Middle Ages has compromised Christians' involvement in the environmental cause. Experimental modern science with its rational and developmental presuppositions contributes to environmental degradation and the separation (dichotomy) of man and nature. The revival of a reformed biblical worldview and the emergence of deep ecology contribute to understanding the environmental crisis.
\end{abstract}

\section{KEYWORDS}

Christian Reformed Worldview, Deep Ecology, Systemic Thought.

\section{INTRODUÇÃO}

Para Wilson (2008, p. 13): "A religião e a ciência são as duas forças mais poderosas do mundo". Elas têm o poder de influenciar milhares de pessoas em torno de vários ideais. E dentre os vários ideais da humanidade, encontra-se a necessidade urgente de resolver três questões criadas pela ordem humanística vigente que 
transforma tudo em mercadoria, da natureza ao sexo e afeta toda a ordem criacional. Essas três questões são problemáticas, pois colocam em xeque a sobrevivência do próprio homem no planeta Terra e são imprescindíveis para a solução da crise ambiental. São elas: a exaustão dos recursos naturais; a (in)sustentabilidade ambiental e a injustiça social (BOFF, 1999). Infelizmente, o antropocentrismo da cultura moderna e uma visão míope e dualista do pensamento cristão ao longo dos vários séculos da tradição teológica, são apontados por muitos pensadores das ciências ambientais, como fatores responsáveis pela crise ecológica civilizacional que contribuem para o aparecimento de outras problemáticas da civilização humana: desigualdade social, doenças, crises econômicas.

Séculos de tradição teológica cristã influenciada pela filosofia pagã, geraram uma compreensão do cosmos dualista, ou seja, dicotomizada em duas esferas distintas: a esfera espiritual e a esfera material. Dessa forma, os cristãos, especialmente do Ocidente, passaram a enxergar o mundo através de dois andares, seguindo a lógica do sagrado e do profano. Com isso, a fé cristã foi relegada à esfera privada e o huma nismo consolidou sua influência na esfera pública mudando a direção das diversas estruturas criacionais: instituições de ensino, ciências, artes, música, negócios etc. Tal concepção explica, pelo menos em parte, a omissão da igreja no engajamento ao debate e solução da crise ambiental, tendo em vista, que na concepção de uma teologia medieval aristotélica e platônica, a salvação representa uma fuga desse mundo e não o enfretamento dessas questões para restaurar a ordem criacional gerada.

De modo semelhante, a ciência moderna pautada no progresso, na racionalidade humana, na tecnologia e no crescimento econômico, tem o método científicolexperimental como base para o conhecimento das leis naturais e a exploração e domínio da natureza. A crença no crescimento econômico e no bem-estar promovido pela revolução técnico-científica, gerou uma sociedade de consumo e autônoma (razão divorciada da fé) desvinculado da Palavra sustentadora de Deus e das normativas para a conduta social. Dessa forma, o sentido primeiro da estrutura criacional foi distorcido, e a criação passou a ser vista como uma fonte inesgotável de recursos naturais para atender o aumento da produção e consumo desenfreado. Com isso, emerge 
a crise ambiental e seus desdobramentos, pois num mundo limitado não pode haver crescimento ilimitado (JUNGES, 2001).

Diante deste cenário, se agravaram os problemas ambientais e a capacidade de suporte do Planeta Terra foi ultrapassada com o aumento da população e do consumo desenfreado. Dessa forma, os sistemas ambientais estão, muitos deles, funcionando hoje no limite do colapso ecológico. Estudo realizado e publicado pela Revista Science em 2015 denominado Os limites planetários: um guia para o desenvolvimento humano num planeta em mutação, revelam que dentre as noves dimensões centrais para a manutenção da vida na Terra, quatro dessas dimensões já estão comprometidas e as demais encontram-se em processo de degradação: mudanças climáticas, perda da biodiversidade, diminuição da camada de ozônio, acidificação dos oceanos, fluxos biogeoquímicos alterados, mudança no uso do solo, uso global da água doce, concentração de aerossóis atmosféricos, introdução de novos matériais sintéticos na natureza (BOFF, 2015).

Tais cenários comprometem a qualidade de vida e a sobrevivência de milhares de pessoas, especialmente as mais vulneráveis socialmente, que dependem diretamente das atividades primárias para o seu sustento. A degradação dos recursos naturais, a desertificação, o degelo, a crise hídrica, a perda da biodiversidade, a poluição do ar e dos mananciais de água doce no mundo, são marcas deixas pela civilização moderna e de um modelo socioeconômico que destituiu a criação do seu plano original transformando-a em um simples depósito de insumos para alimentar a sociedade consumista e materialista fundamentada no humanismo racional, natural e científico.

Sendo assim, é diante deste contexto que este artigo se apresenta, tendo como objetivo principal verificar a contribuição de uma cosmovisão bíblica reformada na compreensão dos problemas ambientais e na promoção da sustentabilidade ambiental. A pesquisa também procura estabelecer a relação entre ecologia profunda e cosmovisão cristã reformada. O trabalho parte da seguinte hipótese: As categorias teológicas Criação, Queda e Redenção são norteadoras para a formação e compreensão de uma cosmovisão bíblica coesa e integral, que contribui para o pensamento ecológico pós-moderno, convergindo com a ecologia profunda e social. 


\section{A CRISE AMBIENTAL E SEUS DESDOBRAMENTOS}

A história da sociedade humana testemunha o aumento contínuo dos impactos ambientais gerados pelas atividades antrópicas sobre o meio ambiente. A partir das civilizações primitivas, constata-se que as atividades de extração dos recursos naturais jamais retrocederam. Na verdade, elas foram cada vez se intensificando com o desenvolvimento de novas descobertas técnico-científicas impulsionadas pela Revolução da Ciência Moderna e o surgimento da Revolução Industrial no século XVIII na Inglaterra. Afirma Wilson (2008, p. 19): "Que a civilização foi alcançada como resultado de uma traição à natureza". Para ele, segundo a compreensão do paradigma da modernidade, pautado no desenvolvimento econômico ilimitado, até o século presente, a natureza parecia infinita e a pauperização da fauna e da flora eram justificadas em nome do progresso.

Nesse sentido, a extração e o consumo dos recursos naturais se intensificaram e as consequências da degradação ambiental ganharam proporções sem precedentes. Tais problemas foram atribuídos à complexidade dos processos de produção e o desenvolvimento econômico ocorrido no decorrer da história da humanidade. Dessa forma, verifica-se claramente que a crise ambiental passa a ser intensificada a partir da Modernidade com o advento da ciência experimental e o "controle" e exploração da natureza. Com a Revolução Industrial, o aumento da produção e a necessidade de um mercado consumidor emergente, intensificaram-se à extração dos recursos naturais, e consequentemente, os diversos impactos ambientais. A moderna revolução técnico-científica e os pressupostos da modernidade - fé no progresso e na razão autônoma - promoveram a falsa ideia de que a vida material das cidades atreladas ao progresso e "felicidade" material seriam suficientes para a satisfação humana (WILSON, 2008).

Ao refletir sobre a crise ambiental e seus desdobramentos, Boff (2015) destaca que a Terra está doente e que o primeiro ser mais ameaçado hoje é o pobre. Segundo ele: $79 \%$ da humanidade vive no Grande Sul pobre; 1 bilhão de pessoas vivem em estado de pobreza; 3 bilhões de pessoas têm alimentação insuficiente; 60 milhões morrem anualmente de fome e 14 milhões de jovens abaixo de 15 anos morrem anualmente em consequência das doenças da fome. Face a esse drama, afirma o 
autor, a solidariedade entre os humanos é praticamente inexistente. A maioria dos países afluentes sequer destina $0,7 \%$ de seu Produto Nacional Bruto (PNB), o preceituado pela ONU, em ajuda aos necessitados. O país mais rico, Estados Unidos, destina apenas $0,15 \%$ de seu PIB. Soma-se a isso a problemática dos imigrantes e refugiados ambientais nos países da Europa e recentemente nos Estados Unidos. Sendo assim, pode-se verificar que os desdobramentos da crise ambiental vão além da questão ecológica e transpõem fronteiras, pois a crise é planetária e humanitária.

Junges (2001) aponta, como um dos desdobramentos da crise ambiental, as chagas sociais que podem ser traduzidas na injustiça, violência e racismo. Tais chagas degradam o convívio humano e manifestam seus efeitos catastróficos no meio ambiente. Ou seja, os problemas ambientais são, ao mesmo tempo, as causas e consequências da distribuição desigual da renda e da exploração social. Dessa forma, afirmar o autor, torna se imprescindível conjugar a preservação do ambiente natural com a ecologia humana e social.

Isso torna-se desafiador no contexto de um modo de produção e de uma cultura do capital que moldou a natureza da ciência econômica (economia clássica), que inicialmente zelava pela administração da casa (oikos), desde os clássicos gregos até o séculoXVIII. E que a partir de então, transformou a economia numa refinada e brutal técnica de criação a acumulação de riqueza (economia de mercado) desvinculada da ecologia (estudo da casa). O capitalismo como modo de produção e como cultura inviabiliza a ecologia ambiental e social (BOFF, 1999).

Mediante este cenário catastrófico da humanidade, a crise ambiental ganhou expressão pública e política a partir da década de 70 com a criação do PNUMA (Programa das Nações Unidas para - Meio Ambiente). A partir desta década, várias reuniões internacionais foram realizadas pela ONU (Organização das Nações Unidas) com o intuito de discutir a crise ambiental, o desenvolvimento econômico e o uso racional (sustentável) dos recursos naturais. Dessa forma, expressões como desenvolvimento sustentável e sustentabilidade ambiental passaram a fazer parte das grandes agendas de governos e das corporações. O debate ambiental sai do meio acadêmico e passa a incorporar a pautar das ONGS, Instituições financeiras, 
corporações e população em geral. Pela primeira vez, o paradigma do modelo desenvolvimentista a qualquer preço é colocado em questão. Ou a sociedade repensa o modelo socioeconômico atual vigente, ou estamos diante de uma catástrofe socioambiental sem precedentes.

Apesar dos inúmeros avanços na pauta do discurso ambiental, muito ainda precisa ser feito, pois torna-se urgente uma visão sistêmica dos problemas ambientais e novos meios de ação política para enfrentá-los (BOFF, 2015). Faz-se necessário uma quebra de uma concepção de mundo baseada no progresso e na infinitude dos recursos naturais. A natureza humana é mais ampla e profunda do que qualquer desenvolvimento técnico-científico civilizacional (WILSON, 2008).

Diante deste contexto dramático, a ciência ecológica profunda e uma cosmovisão cristã bíblica reformada são chamadas a interceder por nós nesses tempos de incertezas e miopia. A nova ecologia deve ser compreendida como um saber de relações, interconexões, interdependências e intercâmbios de tudo com tudo em todos os pontos em todos os momentos (BOFF, 2015). E nesse sentido, a cosmovisão cristã bíblica reformada reafirma a integralidade da ordem criada e contribui com o novo paradigma ecológico, contrariando assim, o pensamento dualistalfragmentado que influenciou por vários séculos o pensamento cristão ocidental e também dicotomizou o pensamento ambientalista, que por muito tempo enxergou o homem separado da natureza e suscitou uma ecologia "rasa", meramente preocupada com as estruturas e funcionamento da casa (oikos) sem levar em consideração as relações sociais, econômicas, culturais e políticas que planejam e organizam a casa. O entendimento integral e abrangente das categorias teológicas Criação, Queda e Redenção torna-se central nessa cosmovisão reformada, tendo em vista, que o objetivo da salvação é salvar a criação corrompida do pecado, ou seja, restaurar não apenas o ser humano do pecado, mas também toda a ordem criada (WOLTERS, 2006). 


\section{O PARADIGMA DUALISTAICARTESIANO NO PENSAMENTO CRISTÃO E NA CIÊNCIA MODERNA E SEUS DEDOBRAMENTOS NA CRISE ECOLÓGICA CIVILIZACIONAL}

A compreensão da crise ambiental planetária requer múltiplos olhares e diálogos. Por isso, uma visão distorcida e fragmentada da realidade pode comprometer o real entendimento dos problemas ambientais e suas múltiplas faces de uma mesma moeda: social, econômico e ecológica. Dessa forma, a superação do pensamento dualistalcartesiano no pensamento cristão e científico torna-se urgente, pois a compreensão do mundo em "andares" proveniente da filosofia pagã e da modernidade, afetou diretamente a teologia e a ciência moderna que se tornou cartesiana, fragmentada, especializada e técnica, sem a compreensão integral e holística dos problemas da humanidade, dentre eles, a crise ambiental civilizacional.

Boas (2012) destaca que as igrejas cristãs, ainda arraigadas no pensamento dualista influenciado pela filosofia pagã de Platão e Aristóteles, pouco contribuem para o enfrentamento e o debate ambiental, pois seus fiéis são orientados a uma vida voltada para o Céu em detrimento da Terra. Indaga o autor: "Como pode um cristão se empenhar na responsabilidade ecológica se para ele a santidade se orienta exclusivamente para o Céu"? Do mesmo modo, a ciência moderna baseada na cultura do capital e na mentalidade do homem econômico, especialmente após a Revolução Industrial, reduz o cosmo a mera fonte de recursos naturais a serem explorados infinitamente para a nossa satisfação material através do consumo. Novamente, indaga o autor: "Como podemos nos sentir incomodados por algo que aparentemente nos beneficia?".

Junges (2001) afirma que os problemas ecológicos questionam os próprios fundamentos da civilização moderna: individualismo, autonomia, ciência, técnica, industrialização, urbanização, consumismo e conforto. A compreensão do ser humano como referência e medida de todas as coisas está sendo criticada, porque criou um distanciamento e até uma oposição entre o humano e o natural. No mesmo sentido dessa compreensão, Goheen e Bartholomew (2016) afirmam que a fé no mito do progresso e nos fundamentos da civilização moderna tem diminuído à medida que o ocidente começou pouco a pouco a entender algumas evidencias do seu fracasso: pobreza, 
degradação ambiental, proliferação de armas, problemas psicológicos e problemas sociais e econômicos.

Infelizmente, por muitos séculos, o pensamento cristão foi influenciado e moldado pela filosofia grega. Os pensamentos de Platão e Aristóteles foram base para a elaboração de uma filosofia e teologia cristã na compreensão do mundo durante todo o período medieval. A dualidade na visão de compreensão do cosmos, o mundo das formas (ideias) e da matéria (natureza), sustentada em dois andares pelo pensamento desses dois filósofos, moldaram a sociedade ocidental por vários séculos com influência no pensamento científico e teológico do período medieval e moderno. Dessa forma, criou-se uma visão distorcida e míope da realidade no enfrentamento dos problemas da humanidade, dentre eles, a crise ecológica da civilização PósModerna, e a compreensão integral e abrangente da ordem criacional.

Vale salientar, que no contexto do Período Medieval, a filosofia cristã Patrística (II - VIII), teve em Santo Agostinho o seu principal expoente. Influenciado por Plotino, Agostinho tenta realizar uma síntese do evangelho com o pensamento de Platão (neoplatonismo). Dessa forma, o elemento neoplatônico pagão, produziu uma orientação transcendental e vertical da compreensão da realidade separando esfera espiritual do mundo material. No contexto dessa interpretação do cosmos, a salvação era a libertação da alma de sua prisão corpórea, permitindo-Ihe ascender a uma esfera superior, invisível e espiritual (GOHEEN; BARTHOLOMEW, 2016). Tal pensamento vai perdurar por todo o Período Medieval, pois na filosofia cristã Escolástica (IX - XVIII), Tomás de Aquino influenciado por Aristóteles elabora um sistema de pensamento baseado em dois andares onde é possível encontrar uma divisão entre o secular e o sagrado. Nos dois andares de Aquino existem a esfera espiritual (alma, igreja, vida cristã, Teologia) e a esfera material (corpo, sociedade, vida cultural, Ciência). Com Aquino, afirmam Goheen e Bartholomew (2016) a razão permanece subordinada a fé, mas uma nova definição de razão é introduzida, pois agora ela serve para examinar as leis da naturezalcriação e das sociedades humanas. Enquanto em Agostinho a razão estava subordinada à fé, em Aquino a razão foi se divorciando da fé. 
Dessa forma, nos séculos subsequentes o andar de cima foi cada vez mais se separando do andar de baixo e a maior parte da vida humana seria separada da autoridade de Deus e do poder do evangelho. Nascia assim, uma natureza autossuficiente divorciada da Palavra sustentadora de Deus e uma sociedade humana autônoma. O indivíduo tornou-se escravo de si mesmo, ou seja, de sua individualização e "liberdade". Dessa forma, estavam lançadas as sementes da ciência moderna, do humanismo confessional, e consequentemente da separação homem Inatureza com as bases da ciência instrumentallexperimental (GOHEEN; BARTHOLOMEW, 2016).

Lançadas as bases da ciência instrumental moderna, a Criação passa a ser vista meramente como insumo para a crescimento econômico ilimitado e o progresso humano. As leis naturais inerentes a Criação são "descobertas" com o instrumental da ciência moderna, e posteriormente, a natureza passa a ser explorada pelo aparato técnico-científico desenvolvido na revolução científica, que passa a ser subserviente ao modelo socioeconômico vigente, que prega a prosperidade material e resolução de todos os problemas via crescimento econômico. A ciência passa a ser a "solução" e a "religião", para muitos que enxergam nesse novo paradigma baseado na racionalidade humana, no progresso e desenvolvimento econômico, a solução para os problemas da humanidade.

Como bem afirma, Junges (2001), enquanto para o Gregos no período clássico havia uma diferença básica entre ciência (conhecimento do equilíbrio e da harmonia do mundo) e técnica (saber instrumental e empírico sobre questões de aplicação pragmática), pois o saber científico era superior e estava diretamente atrelado ao interesse intelectual da compreensão do cosmos sem objetivar interesses concretos le ou aplicabilidade, na ciência moderna, o conhecimento científico precede o aperfeiçoamento da técnica para fins de exploração da natureza, o que ocorre mais tarde com a Revolução técnico-científica. Tal desenvolvimento foi possível pela transição da concepção clássica (ciência contemplativa) para a concepção moderna (ciência ativa).

Ainda na concepção de um mundo dualista (de dois andares) e agora pautado pelo paradigma da ciência moderna, o inglês Francis Bacon compreende que a reconciliação do relacionamento com Deus é tratada pela religião por meio da fé. $\mathrm{E}$ 
que, o domínio da natureza ordenado por Deus no Éden, se reconciliaria através da ciência e tecnologia. Complementando o método empírico e experimental de Bacon, Descartes apresentava um método racionalista matemático e Newton consolidaria o método científico que originaria as ciências naturais e mais tar de a dicotomia entre ciências humanas e naturais, o que dificultaria a compreensão integral do cosmos. (GOHEEN; BARTHOLOMEW, 2016). Nesse contexto, a natureza não é mais uma realidade a ser conhecida em si mesma, ou contemplada, mas uma realidade na qual o ser humano deve intervir para seu próprio interesse e deleite. (JUNGES, 2001). Daí surge a crise ambiental moderna e seus desdobramentos.

Dessa forma, a crise ecológica dá lugar ao questionamento dos paradigmas que sustentam a ciência moderna compartimentada, dicotomizada e instrumental sem uma visão de conjunto da realidade. Faz necessário um conhecimento que seja holístico, interdisciplinar e coeso que dialogue com as diversas áreas do conhecimento.

Os paradigmas que sustentaram a modernidade e o pensamento cristão dualista (profano e sagrado) são colocados em questionamento, pois a tradição cristã de dois "andares", a autonomia do indivíduo, a fé na racionalidade humana, no progresso e na ciência, criaram um modelo de sociedade antropocêntrica, descartável e hedonista que contribuíram diretamente para a crise ambiental planetária. Assim, não se fica nem na heteronomia da tradição, nem na autonomia da modernidade, mas no niilismo da Pós-Modernidade. (BOAS, 2012).

Nesse sentido, cosmovisão cristã reformada e ecologia profunda são essenciais para a compreensão desta realidade complexa e integral, pois faz-se necessário a superação do paradigma mecanicista da ciência moderna para uma ciência relacional e interdisciplinar. Da mesma forma, é preciso superar o paradigma dualista de dois andares e caminhar rumo a uma teologia coesa e integral que dialoga em categorias cientificas e teológicas rumo a um campo de conhecimento público que possa afetar todas as esferas da sociedade. Dessa forma, ciência e fé precisam urgentemente se unir para estabelecerem um diálogo harmonioso em prol da sustentabilidade ambiental planetária. 


\section{COSMOVISÃO CRISTÃ REFORMADA E ECOLOGIA PROFUNDA: UM DIÁLOGO NECESSÁRIO}

A superação do paradigma clássico (forma e matéria) que moldou a tradição teológica do pensamento cristão, bem como, do pensamento humanístico (naturezaViberdade) que influenciou e influencia a sociedade moderna e pós-moderna perpassa por uma ruptura de valores e percepções. Para a superação de tais paradigmas (clássico e moderno), serão necessárias modificações radicais de nossos valores, estilos de vida e instituições em geral. Deve ficar claro para a humanidade que depois de satisfazer nossas necessidades básicas, o próximo passo é fundamentalmente tornarmo-nos melhores e não mais acumular riquezas e poder. (FERRERO; HOLAND, 2004). Para satisfazer essas aspirações é imprescindível o senso de responsabilidade universal, o respeito e cuidado com a comunidade da vida, a integralidade ecológica e a promoção da justiça econômica e responsabilidade social, bem como, uma cultura de paz e cooperação entre todos os povos, afirmam Ferrero e Holland (2004) destacando a Carta da Terra (declaração de princípios éticos fundamentais para a construção, no século XXI, de uma sociedade global justa, sustentável e pacífica).

Dessa forma, como superação da visão dicotomizada e cartesiana da ciência moderna surge a Ecologia Profunda que tem como seus principais expoentes: Arne Naess, Frijolt Capra, Leonardo Boff, dentre outros. E como superação do pensamento cristão dualistalfragmentado, influenciado pela filosofia pagã grega, surge a Cosmovisão Cristã Bíblica Reformada, que teve na escola de pensamento holandês Neocalvinista um sistema teológico e filosófico contextualizado e coeso correlacionando o Calvinismo com os problemas da atualidade. Os principais expoentes desse movimento são: Abraham Kuyper, Hermann Bavinck e Hermann Dooyeweerd.

Verifica-se que existe uma intersecção entre essas duas áreas do conhecimento - ciência ecológica profunda e cosmovisão cristã reformada - pois ambas procuram compreender a totalidade e integração de todas as coisas. Como já dito anteriormente por Wilson (2008), a religião e a ciência são as duas forças mais poderosas do mundo. Sendo assim, ambas devem unir forças em prol da compreensão e superação da crise ambiental civilizacional 
global e do paradigma dualista Icartesiano que moldou a civilização ocidental por vários séculos e separou o homem da natureza.

Para a ecologia profunda, a crise ambiental atual é a crise da civilização, ou seja, é a crise do nosso atual paradigma dominante, do nosso modelo de relações sociais, de nosso sentido de viver preponderante. Com a consciência que a sociedade tem hoje, seria irresponsável e antiético continuar na mesma direção (BOFF, 2015). A necessidade de ruptura de paradigma é urgente e indispensável para garantir a sobrevivência da humanidade no Planeta Terra. O surgimento de um novo paradigma pautado na ciência ecológica profunda que mergulha em questões éticas e morais para se compreender a crise ambiental, faz-se necessário para destronar os valores materiais da sociedade atual. Nesse sentido, mudanças no ponto de vista da sociedade são emergentes, pois os sistemas vivos não são lineares e estão baseados em padrões de relacionamento (integralidade).

Para entender este novo paradigma emergente (ecológico) é preciso uma nova maneira de pensar e enxergar a vida. É preciso uma "conversão" ecológica que perpassa inicialmente por uma conversão e cosmovisão cristã reformada. Aqui a cosmovisão bíblica reformada (teologia pública) pode auxiliar mais diretamente a ecologia, como sua interlocutora na fé das pessoas e na revolução cultural da sociedade através de um pensamento de mundo integral, abrangente, coeso e normativo de enxergar a vida, destaca Boas (2012, p. 170). Ainda afirma o autor: "A interlocução da teologia não deve ser restringir às pessoas de fé, mas deve ser entendida como parceira social na luta por uma causa que é de todos, procurando colaborar na reflexão séria da questão da ética em busca da excelência da vida". O movimento ecológico hodierno não se prende à ecologia natural, como se fosse um capítulo da biologia (BOAS, 2012). Pelo contrário, ele é amplo, relacional, complexo e holístico e depende de mudanças profundas de valores e atitudes da civilização humana que perpassam pela cosmovisão cristã reformada e uma teologia de caráter público.

Para Capra et.al (2006) esta nova maneira de pensar de forma contextualizada e sistêmica a vida, implica em várias mudanças de ponto de vista: da parte (paradigma atual) para o todo (novo paradigma emergente); dos objetos (paradigma atual) para as relações (novo paradigma emergente); do conhecimento 
objetivo (paradigma atual) para o conhecimento contextual (novo paradigma emergente); da quantidade (paradigma atual) para a qualidade (novo paradigma emergente); da estrutura (paradigma atual) para o processo (novo paradigma emergente); dos conteúdos (paradigma atual) para os padrões (novo paradigma emergente).

Sendo assim, a compreensão de uma cosmovisão cristã bíblica reformada contribui diretamente para o entendimento holístico e coeso da crise de civilização e superação de tais problemas pelos quais perpassam a sociedade Pós-Moderna. Fundamentada na quebra do paradigma dualista que perdurou por muitos séculos o pensamento cristão do ocidente, a cosmovisão cristã bíblica reformada baseada na análise da narrativa bíblica, especialmente pela escola Neocalvinista, elenca três categorias chaves teológicas - Criação, Queda e Redenção - e um sistema filosófico cristão para a compreensão do drama da humanidade nas escrituras e a restauração de todas as coisas. É nesse contexto que se fala de uma cosmovisão cristã abrangente, coesa e normativa em que os pensadores holandeses mencionados anteriormente, vêm sendo valorizados em nossos dias atuais. (RAMLOW, 2012).

A partir dessa compreensão integral e holística do pensamento cristão, é possível uma interlocução de uma teologia, agora de caráter público, com a ciência da ecologia profunda, pois uma cosmovisão cristã reformada e coesa abrange todas as esferas da sociedade na restauração de todas as coisas. Uma teologia pública é a presença cristã nas diversas instâncias da sociedade civil, afirma Cunha (2015). Continua Pearcey (2006) um dos propósitos primários da religião (teologia) é prover um senso de significado para a vida. Dessa forma, ao se permitir que ela fique privada e segregada rebaixa-se um dos seus propósitos primários, permitindo assim, que a estrutura original criacional seja distorcida (direção). E, por outro lado, ao se permitir seu discurso e contribuição no âmbito público, possibilita-se a restauração da ordem criacional (estrutura) para o estado original antes da Queda (pecado). Como bem destaca a autora, "Estrutura" diz respeito ao caráter criado do mundo, que ainda é bom mesmo depois da Queda. Já "Direção" refere-se ao modo como "dirigimos" essas estruturas para servir a Deus ou aos ídolos. Dessa forma, pode-se afirmar que toda a Criação é boa. Mas o pecado tem o poder de direcionar toda e qualquer ordem criada para os ídolos. Dessa 
forma, a crise ambiental pode ser compreendida como uma distorção da Criação de seu propósito original para o ídolo do progresso e do desenvolvimento econômico ovacionado pelo humanismo. No entanto, no Drama da Escrituras Bartholomeu e Goheen (2017) afirmam que toda a história terá um fim, pois a Restauração realizada por Deus será progressiva, total e abrangente, atingindo assim, toda a Criação.

Bartholomew e Goheen (2016), destacam que uma teologia pública reformada com suas categorias de análise e um sistema filosófico coeso que explica toda a crise civilizacional passa a ser compreendida como uma cosmovisão cristã reformada. E que dessa forma, o entendimento bíblico passa a ser visto como uma metanarrativa da história do mundo. Conforme Bartholomew e Goheen (2017, p. 15): “A história bíblica não avança na destruição do mundo e do nosso próprio "resgate" ao céu". Em vez disso, ela culmina na restauração de toda a Criação à sua virtude original". O objetivo da salvação é restaurar toda a criação corrompida pelo pecado.

No contexto dessa metanarrativa, a partir da criação, Deus expõe sua vontade e ordenamento sobre todas as coisas. Com isso, Ele impõe sua lei sobre o cosmos agindo de modo direto, através da natureza, ou indiretamente, pelo envolvimento da responsabilidade humana nas diversas esferas da sociedade. Tanto as leis naturais como o ordenamento social através das normas, pertencem à lei universal criada por Deus para toda a criação. (WOLTERS, 2006). A responsabilidade humana deve estar condicionada às normas estabelecidas para o Reino. Só assim, o pecado (crise ambiental) será extirpado da face da Terra (restauração \nova criação). Destaca Wolters (2006, p. 58): “O novo céu e a nova terra que o Senhor prometeu será uma continuação, purificada pelo fogo, da criação que agora conhecemos".

Nesse drama das escrituras, a Queda afetou diversas esferas da sociedade e promoveu a morte espiritual, teológica, sociallrelacional e ecológica. A crise ambiental é fruto do pecado cometido por Adão e Eva em desobediência as leis e normas do Senhor para a Criação. No entanto, com o início do processo gradual e progressivo da Restauração, ocorrido logo em seguida após episódio da Queda e culminando na inauguração do Reino de Deus com a morte e ressureição de Cristo na cruz, a igreja é proclamada a estabelecerlpromover o Reino de Deus aqui na 
Terra. Daí emerge a responsabilidade dos cristãos em atuar nas diversas esferas da sociedade restaurando toda a ordem criacional. Os cristãos devem lutar pela causa ambiental no entendimento da missão de anunciar o Reino do Senhor aqui na Terra. O seu estabelecimento requer a restauração de toda a Criação iniciado por nós e concluída na segunda vinda de Cristo.

É nesse contexto que a cosmovisão cristã reformada teologia pública - e a ecologia profunda - baseada no pensamento sistêmico - desenvolvem um diálogo necessário na promoção da sustentabilidade ambiental. A nova ecologia requer uma atitude ética e mudanças de valores, e nesse caso, a cosmovisão cristã reformada é imprescindível para a conversãoltransformação integral do homem, o estabelecimento de uma ética universal e a restauração de toda a criação. Como afirma Boas (2012) a teologia e a ecologia podem juntas colaborar para ampliar o horizonte de responsabilidade do ser humano para uma compreensão mais ampla do valor da vida e restauração da ordem criacional.

Dessa forma, esse novo paradigma que emerge desafia a tradição teológica pautada no dualismo (profano sagrado) e os pressupostos da ciência moderna experimental. Os frutos desse diálogo entre cosmovisão cristã reformada (teologia pública) e ecologia profunda, assinala Cunha (2012) são percebidos através da consciência de abertura de um diálogo com outras áreas do conhecimento, a transdiciplinaridade e a criatividade. A cosmovisão cristã reformada possibilita uma teologia pública que significa a ética do Reino sendo implantada nas diferentes esferas da sociedade civil e a chave para desatar o nó da crise ambiental e restaurar todas as coisas.

\section{CONSIDERAÇÕES FINAIS}

A crise ambiental é fruto de uma crise civilizacional pela qual passa a sociedade pós-moderna. Ela foi construída historicamente através dos pressupostos do humanismo confessional que enxerga no progresso, na racionalidade humana e na ciência experimental, a realização plena (shalom) para a humanidade. A fé no desenvolvimento econômico, no progresso, na razão humana e na ciência experimental gerou a ilusão de um crescimento material ilimitado descompromissado com a sustentabilidade ambiental, social e econômica do planeta Terra. A 
pilhagem da natureza, o colapso das terras férteis, as mudanças climáticas globais, a perda da biodiversidade e os problemas econômicos e sociais, são alguns sinais apocalípticos de um modelo de sociedade antropocêntrica, egocêntrica, individualista, materialista, fragmentada e ultrapassada.

Além disso, a visão de mundo dicotomizada e dualista do pensamento cristão tradicional (sagrado e profano) descontextualizada da sociedade, gerou a omissão de muitos cristãos pela causa ambiental e potencializou a exploração da natureza pela revolução técnico-científica, separando assim, cada vez mais o homem da natureza. O mito do progresso material sem limites e a "fuga" para o céu de muitos cristãos, formaram o terreno fértil para o desencadeamento de toda a crise civilizacional ambiental.

A necessidade de mudanças é urgente. E o novo paradigma civilizacional emerge de um saber holístico, sistêmico, transdisciplinar, integrador, abrangente e coeso. A ética global para uma sociedade sustentável, requer uma mudança de valores e atitudes. Requer uma aliança global entre as diversas formas de saberes e experiências. Requer um diálogo constante e criativo aberto as discussões. Requer uma ciência ecológica profunda e uma teologia pública.

E é nesse cenário caótico de incertezas e mudanças, que uma cosmovisão cristã reformada (teologia pública) e a uma ciência ecológica (profunda) se encontram em prol de um objetivo comum: restaurar toda a Criação. A mudança de valores e atitudes perpassa por uma "conversão" ecológica que precede uma conversão cristã genuinamente. É preciso "ecologizar" os saberes e submetê-los ao senhorio de Cristo que redime todas as coisas na cruz do calvário. A Criação, a Queda e a Restauração representam o drama do ser humano no relato bíblico. A compreensão desse drama nos dá uma cosmovisão cristã reformada, coesa, abrangente e integradora para o entendimento, interpretação e definição da missão integral dos cristãos no mundo. Um cristianismo integral, vivenciado sob a ótica da cosmovisão cristã reformada, é a proposta do Criador frente a uma teologia alienada e fragmentada pelo pensamento dualista grego pagão voltada para apenas para Céu.

Por fim, é diante deste contexto, que a cosmovisão cristã reformada através da escola de pensamento Neocalvinista, 
colabora através de uma teologia reformada de alcance público, e de um sistema filosófico coeso e abrangente, para a promoção da sustentabilidade ambiental. Cosmovisão cristã reformada e ecologia profunda cumprem assim o papel - através da responsabilidade humana - de promover o Reino de Deus aqui na Terra como no Céu através da restauração de toda a Criação. $\mathrm{E}$ comprova o diálogo salutar entre fé (teologia pública) e ciência (ecologia profunda) na busca por uma sociedade economicamente viável, socialmente justa e ecologicamente sustentável. 


\section{REFERÊNCIAS}

BARTHOLOMEW, C.G.; GOREEN, M.W. O Drama das Escrituras. São Paulo/SP: Vida Nova, 2017.

BOAS, A.V. Meio Ambiente e Teologia. São Paulo/SP: SENAC, 2012.

BOFF, L. Ecologia: grito da Terra, Grito dos Pobres. Petrópolis/R]: Vozes, 2015.

BOFF, L. O Ecocídio e o biocídio. In: ARAÚJO, A.; SADER, E.; BETTO, F.; STÉDILE, J.P.; BOFF, L.; KEHL, M.R.; FELINTO, M.; SANTOS, M. 7 Pecados do Capital. Rio de Janeiro/RJ; São Paulo/SP: Record, 1999.

CAPRA, F.; Alfabetização Ecológica: a educação das crianças para um mundo sustentável. São Paulo/SP: Cultrix, 2006.

CUNHA, C.A.M. Ecoteologia pública: contribuições do pensamento sistêmico de Fritjof Capra à epistemologia da teologia. Anais do V Congresso da ANPTECRE - religião, direitos humanos e Laicidade. Curitiba/PR, v. 5, 2015.

FERRERO, E.M.; HOLLAND, J. Carta da Terra: reflexão pela ação. São Paulo/SP: Cortez, 2004.

GORREN, M.W.; BARTHOLOMEW, C.G. Introdução à Cosmovisão Cristã: vivendo na intersecção entre a visão bíblica e a contemporânea. São Paulo/SP: Vida Nova, 2016.

JUNGES,J.R.; Ecologia e Criação. São Paulo/SP: Loyola, 2001.

LEITE, C.A.C.; CARVALHO, G.V.R.; CUNHA, M.J.S. Cosmovisão cristã e transformação. Viçosa/MG: Ultimato, 2006.

PEARCEY, N. Verdade Absoluta. Rio de Janeiro/RJ, CPAD, 2006.

RAWLOW, R.R. O Neocalvinismo Holandês: autores e temas. Anais do Congresso Internacional da Faculdade EST. São Leopold/RS: EST, v. 1, 2012.

WILSON, E.O; A Criação: como salvar a vida na Terra. São Paulo/SP: Companhia das Letras, 2008.

WOLTERS, A.M. A Criação Restaurada: base bíblica para uma cosmovisão reformada. São Paulo/SP: Cultura Cristã, 2006. 